Patients who have undergone bilateral carotid endarterectomy may be insensitive to hypoxia due to carotid body trauma with resulting increased sensitivity to narcotics and barbiturates. ${ }^{2}$ This patient, however, did not respond to naloxone and subsequently received opiates with no untoward effect.

In a procedure such as carotid endarterectomy the effects of changes in cerebral perfusion must also be considered. Most patients tolerate unilateral carotid clamping, but individual variability in the circle of Willis might cause problems. The method of ventilation also affects cerebral perfusion. Hypercapnia, which is likely during spontaneous ventilation, increases total cerebral blood flow but may produce cerebral steal syndromes which decrease flow to areas where perfusion is critical. ${ }^{3}$ We suggest that the combination of these factors may have been responsible for this patient's problem, the resultant hypoperfusion during carotid clamping producing a degree of mid-brain oedema with resultant respiratory depression. At present there is no clear opinion ${ }^{4}$ on the choice between spontaneous and artificial ventilation, but the experience of this case may favour the latter since the first procedure was uneventful.

An unusual feature was the return of spontaneous ventilation with the suction cap in place. Possibly the slight positive pressure generated by the full reservoir bag against the opening resistance of the Heidbrink valve stimulated reflex respiratory activity, the picture seen being akin to Head's paradoxical reflex. ${ }^{5}$

We thank Dr H W C Griffiths and Mr M G Walker for permission to report details of this case.

${ }^{1}$ Fields, W S, et al, fournal of the American Medical Association, 1970, 211, 1993.

2 Wade, J G, et al, New England fournal of Medicine, 1970, 282, 823.

${ }^{3}$ Boysen, G, et al, Anesthesiology, 1971, 35, 286.

${ }^{4}$ Fitch, W, British fournal of Anaesthesia, 1976, 48, 791

${ }^{5}$ Fenn, W O, and Rahn, H, Handbook of Physiology, Section 3, Respiration.

Washington, DC, American Physiological Society, 1964.

(Accepted 3 October 1978)

Department of Anaesthetics, Royal Infirmary, Edinburgh EH3 9YW

DAVID BEAMISH, MB, FFARCS, senior registrar

J A W WILDSMITH, MB, FFARCS, consultant by the left kidney, but an aortogram showed normal renal vessels, and a gammacamera renogram was normal.

Treatment and progress-Oral hydrallazine and propranolol caused postural hypotension, without effect on recumbent blood pressure or the symptoms of headache, anorexia, misery, and pain in the arms. Thirteen days after admission the blood pressure rose to $190 / 150 \mathrm{~mm} \mathrm{Hg}$, and he suffered severe headache. Intravenous diazoxide, $150 \mathrm{mg}$ with a further $300 \mathrm{mg}$ after three hours, lowered the blood pressure to $160 / 110 \mathrm{~mm} \mathrm{Hg}$; it was thereafter controlled with propranolol $80 \mathrm{mg}$ and hydrallazine $37.5 \mathrm{mg}$ (both three times a day), being $125 / 90 \mathrm{~mm} \mathrm{Hg}$ on discharge 39 days after admission. Twelve weeks after the onset of chickenpox his weight, mood, and personality had recovered. His shoulder girdle muscles, however, were wasted, with winging of the scapulae and a right wrist drop (see figure). All muscles innervated by cervical roots 5-8 on the right and 5-7 on the left were weak. Tendon reflexes in the arms were reduced. Sensation was normal Reduced conduction velocity of the right radial nerve was shown five month after the onset of chickenpox. Electromyography suggested partial denervation of the affected muscles.

The antihypertensive drugs were gradually withdrawn 14 to 17 weeks after the onset of chickenpox. One year later the blood pressure remained at $120 / 80 \mathrm{~mm} \mathrm{Hg}$ lying down; it was difficult to assess when he was standing because of indeterminate Korotkoff sounds and narrow pulse pressure. Muscle power continued to improve, with normal everyday function bu residual weakness.

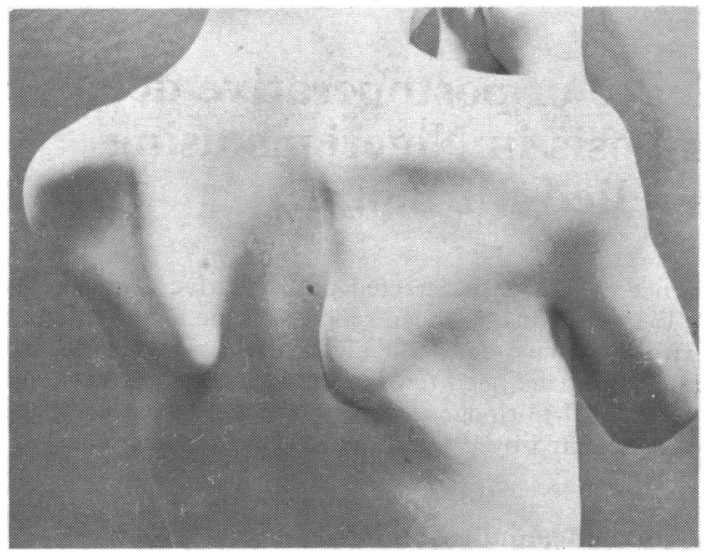

Winging of scapulae.

\section{Transient severe hypertension and polyradiculitis after chickenpox}

Chickenpox can cause encephalitis, cerebellar ataxia, myelitis, polyradiculitis, ${ }^{1-3}$ and glomerulonephritis, ${ }^{45}$ but transient postvaricella hypertension with neurological, but no renal, complications has not been reported. We describe such a case.

\section{Case report}

A healthy 12-year-old boy was recovering from chickenpox when, two weeks after onset, he suffered pain, tenderness, and weakness in the right upper arm and later in the left. Next day he developed headache, vomiting, misery, and weakness; these symptoms worsened until he was admitted to hospital, three weeks after the onset of chickenpox. On admission he was orientated but drowsy and irritable, with weight loss, chickenpox scabs, a pulse rate of 96 beats $/ \mathrm{min}$, an oral temperature of $37.2^{\circ} \mathrm{C}$, blood pressure varying between $140 / 110 \mathrm{~mm} \mathrm{Hg}$ and $165 / 140 \mathrm{~mm} \mathrm{Hg}$, normal volume femoral pulses, normal optic fundi, and an apex beat of normal position and impulse. The right upper arm was tender. Movement of both elbows was weak and flexion and extension of the hips slightly weak. All tendon reflexes were reduced, the ankle jerks and plantar responses being absent.

Investigations-Repeated urine analysis showed occasional slight proteinuria but no erythrocytes, leucocytes, or organisms. The following investigations and values showed no abnormality: urine culture; full blood count and erythrocyte sedimentation rate; serum electrolytes, urea, and creatinine concentrations; serum protein electrophoresis; immunoglobulins, $\mathrm{C} 3$, C4, activated $\mathrm{C} 3$, and total haemolytic complement; $\mathrm{C} 3$ split products antinuclear factor; LE cells; sheep cell agglutination test; anti-DNA antibodies; cerebrospinal fluid pressure, cells, protein, and glucose; urinary catecholamines; chest radiography; electrocardiography; electroencephalography; intravenous phentolamine test; and virus culture of throat swab and cerebrospinal fluid. An intravenous pyelogram showed delayed excretion

\section{Comment}

The severe headache, vomiting, and personality change might hypertension was excluded by the absence of papilloedema, raised cerebrospinal fluid pressure, and electroencephalographic changes. No abnormality was found in the renal or immune systems, rendering postvaricella glomerulonephritis unlikely as a cause for the hypertension. The muscle wasting was attributable to postvaricella polyradiculitis of the fifth to eight cervical roots; evidently some other, perhaps autonomic, nervous-system lesion disturbed the control of blood pressure, causing temporary hypertension and persistent postural lability of blood pressure.

We thank Professor I B Houston, Royal Manchester Children's Hospital, for taking over the patient at a critical time and for his helpful criticisms, and Dr M J Noronha, Booth Hall Children's Hospital, Manchester, for carrying out nerve conduction and electromyography studies.

1 Brain, W, British Medical fournal, 1931, 1, 81.

2 Bullowa, J G, and Wishik, S M, American Fournal of Diseases of Children, 1935, 49, 923.

${ }^{3}$ Miller, H G, Stanton, J B, and Gibbons, J L, Quarterly Fournal of Medicine, 1956, 25, 427.

${ }^{4}$ Minkowitz, S, et al, American fournal of Medicine, 1968, 44, 489.

${ }^{5}$ Pedersen, F K, and Petersen, E A, Acta Paediatrica Scandinavica, 1975, 64, 886.

(Accepted 5 October 1978)

Devonshire Road Hospital, Barrow-in-Furness, Cumbria LA14 5NF JOANNE DAVIES, medical student (now house physician, Withington Hospital, Manchester)

R J ROWLATT, MB, MRCP, consultant paediatrician indicate encephalitis, but intracranial hypertension causing systemic 